\title{
Pathology of spleen in chickens fed on a diet deficient in methionine
}

\author{
Bangyuan Wu, Hengmin Cui ${ }^{*}$ Xi Peng, Jing Fang, Wei Cui, Xiaodong Liu \\ Key Laboratory of Animal Diseases and Environmental Hazards of Sichuan Province, College of Veterinary Medicine, Sichuan Ag- \\ ricultural University, Ya'an, China; ${ }^{*}$ Corresponding Author: cui580420@, sicau.edu.cn
}

Received 15 November 2011; revised 6 December 2011; accepted 16 December 2011

\section{ABSTRACT}

The purpose of this 42-day study was to investigate the effects of methionine deficiency on spleen by determining the relative weight, morphological changes of spleen, cell cycle and apoptosis of splenocytes, and oxidative markers of serum and spleen. One hundred and twenty one-day-old avian broilers were randomly divided into two groups and fed on a control diet

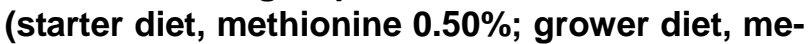
thionine $0.40 \%$ ) and methionine deficient diet (starter diet, methionine $\mathbf{0 . 2 6 \%}$; grower diet, methionine $0.28 \%$ ) for 6 weeks. The relative weight of spleen was lighter in methionine deficiency than control group. Histopathologically, lymphopenia and congestion were observed. Ultrastructurally, there were more apoptosis lymphocytes in spleen and the mitochondria of lymphocytes were swelled in methionine deficiency. By flow cytometry, the $G_{0} / G_{1}$ phase of the cell cycle of the spleen was much higher $(P<0.01)$, and the $S$, $\mathrm{G}_{2}+\mathrm{M}$ phases and proliferating index were lower $(P<0.01)$ in methionine deficiency than in control group. And the percentage of apoptotic cells in the spleen was significantly increased in methionine deficiency $(P<0.01)$. The superoxide dismutase and glutathione peroxidase activities, and abilities to inhibit hydroxyl radicals were greatly decreased while the malondialdehyde contents were markedly increased in methionine deficiency. It was concluded that methionine deficiency could restraine the development of the spleen by cell cycle arrest and increased apoptosis, cause splenic lesions and reduce splenic antioxidant function. The splenic function should be finally impaired and then the immune function could be impacted in chickens.

Keywords: Methionine Deficiency; Spleen; Lesions; Antioxidant Function; Flow Cytometry; Broiler

\section{INTRODUCTION}

Methionine (Met) is the first limiting essential amino acid, which is a source of sulfur in the diet, a source of methyl groups and a means of transporting these onecarbon units in metabolic pathways, and therefore, interacting with folate, vitamin B12 and choline, and Met is the initial amino acid in polypeptide-chain synthesis [1, 2]. One essential function of Met in neurulation may be as precursor for S-adenosylmethionine (SAM), the methyl donor in transmethylation reactions [3], which plays a main role as the biological methyl donor for the methylation of DNA, RNA, and protein [4]. A deficiency of Met depresses both the amount of food consumed and body weight gain and Met deficiency is a cause of nutritional myopathy [5]. Moreover Met is a protective factor against various types of liver damage [6,7].

Apart from the abovementioned functions, Met is also involved in avian immune functions. For instance, Met promotes antibody production and cell-mediated immune responses in broiler chickens [8-10]. Met is required for select components of the antibody response, which might be related to T-cell help [9]. Met is also required for production of a cytokine, interleukin-1, in immunologically challenged chicks [11]. And Met deficiency has specific effects on immune responses, which can affect cell mediated immune responses relative to development of the lymphoid organs and antibody production in chickens [12]. Thus, Met deficiency can potentially interfere with any or all of the known mechanisms of worm expulsion whether antibody production and cell-mediated immunity, or mucosal mast cells are interfered with by a number of metabolic pathways [2]. And it is report that cells (both proliferating PC12 cells and postmitotic neurons isolated from fetal rat brains) undergo apoptosis when deprived of other individual essential nutrients (such as methionine) [13]. However, Met is the most toxic of the amino acids in rats, and an excess of a single amino acid often results in an imbalance $[14,15]$.

According to references aforementioned, there have been few systematic reports on effect of Met deficiency 
on spleen in broilers so far. In the present research, the experiment was conducted with the objective of examining the effects of Met deficiency on the spleen of chicken by methods of experimental pathology and flow cytometry (FCM), which provides helpful materials for the same or similar studies in both human and other animals in the future.

\section{MATERIALS AND METHODS}

\subsection{Diets and Chickens}

Experimental diets were formulated by NRC (1994). The Met content of Met deficient diet was measured by HITACHI L-8800 automatic Amino Acid analyzer. The results showed that the Met content was $0.26 \%$ in starter diet, and $0.28 \%$ in grower diet. $0.24 \%$ and $0.12 \%$ Met were added to Met deficient diet to produce control diets (starter diet, Met $0.50 \%$; grower diet, Met $0.40 \%$ ).

120 one-day-old healthy avian broilers were randomly allotted by body weight to 2 groups with 6 replicates each group and 10 broilers in each replicate. Broilers were fed on a control diet or Met deficient diet, and were housed in cages with electrically heated units and were provided with water ad libitum for 42 days.

The use of chickens in our experiments was followed and all experimental procedures involving animals were approved by Sichuan Agricultural University Animal Care and Use Committee.

\subsection{Clinical Signs and Relative Weight of Spleen}

Clinical signs were observed everyday. At 7, 14, 21, 28,35 , and 42 days of age during the experiment, five birds in both groups were euthanized and necropsied after the body weight was weighed. The macroscopic changes of spleens were observed and recorded. Spleen was dissected from each chick, and weighed after dissecting connective tissue around the organ. Related Weight $(\mathrm{RW})$ of spleen was calculated by the following formula:

$\mathrm{RW}=$ organ weight/body weight $(\mathrm{g} / \mathrm{kg})$.

\subsection{Pathological Observation in the Spleen}

After weighed, spleen was fixed in $4 \%$ buffered formaldehyde and routinely processed in paraffin. Thin sections $(5 \mu \mathrm{m})$ of each tissue were sliced from each block and mounted on glass. Slides were stained with hematoxylin and eosin (H\&E). Histological slides were examined under an Olympus light microscope (made in Japan).

At the end of the experiment (42 days of age), 3 chickens in each group were euthanized and then immediately necropsied. Spleens were sampled for ultrastruc- tural observation, as described by Peng et al. [16].

\subsection{Cell Cycle of Spleen}

At 14, 28, and 42 days of age, five chickens in both groups were selected for the determination of the cell cycle stages in the spleens by flow cytometry, as described by Cui et al. [17].

\subsection{Annexin-V Apoptosis Detection by Flow Cytometry}

At 14, 28, and 42 days of age during the experiment, five birds in each group were euthanized. Spleen was sampled from each chick for the determination of the percentage of apoptotic cells by flow cytometry as described by Peng et al. [16].

\subsection{Tunel Assay}

Terminal deoxynucleotidyl transferase 2 -deoxyuridine 5'-triphosphate dUTP nick end-labeling (TUNEL) assay was performed in deparaffinized sections ( $5 \mu \mathrm{m}$ thick) with an Apoptosis Detection Kit(Merck)according to the suppliers' instructions. Briefly, tissue sections were rehydrated in a series of xylene and ethanol solutions and then incubated at room temperature for $20 \mathrm{~min}$ with Proteinase K (Cata.No.JA 1477) in a humidified chamber. Slides were then rinsed in Tris-buffered saline(TBS). The entire specimens were covered with $3 \% \mathrm{H}_{2} \mathrm{O}_{2}$ and then incubated at room temperature for $5 \mathrm{~min}$. Slides were rinsed with TBS.TUNEL enzyme (Cata.No.JA 1559) and label solution (Cata.No.JA 1560) were mixed and applied to the tissues, which were incubated again in the humidified chamber for $1 \mathrm{~h}$ at $37^{\circ} \mathrm{C}$. Slides were rinsed thoroughly in TBS. Stop solution; block solution, and conjugate were applied by turns. Diaminobenzidin solution was applied for 10 - 15 min to stain the nuclei of apoptotic cells. The methyl green solution was used to counter stain the nuclei of normal cells. Tissues were dehydrated in a series of three ethanol baths and two xylene baths for 5 min each.

\subsection{Detection of Oxidative Markers in the Serum and Spleen}

At 14,28 , and 42 days of age during the experiment, five chickens in each group were phlebotomized from jugular vein to obtain serum. Then, the chickens were humanely killed and the spleens were taken immediately. Spleens were homogenized and centrifuged, and were then made into homogenate through cell homogenizer in ice path. After determining the amount of total protein and albumin in the supernatant of the splenic homogenate and the serum by the method of Bradford [18], the superoxide dismutase (SOD), and glutathione peroxidase 
(GSH-Px) activities, abilities to inhibit hydroxyl radicals and the malondialdehyde (MDA) contents in the splenic supernatant and serum were detected by biochemical method following the instruction of reagent kits. The reagent kits for measurement of SOD (Cata.No. A001-1) and GSH-Px (Cata.No.A005) activities, and MDA (Cata. No.A003) contents and abilities to inhibit hydroxyl radicals (Cata.No.A018) were purchased from Nanjing Institute of Jiancheng Biological Engineering.

\subsection{Statistical Analysis}

The significance of difference between two groups was analyzed by Independent Sample T Test analysis, and results presented as means \pm standard deviation $(X \pm \mathrm{SD})$. The analysis was done under SPSS 12.0 for windows.

\section{RESULTS}

\subsection{Clinical Observation}

Broilers grew slower in Met deficiency than in control group. Broilers in Met deficiency showed slightly decreased feed intake and depression.

\subsection{Changes of Weight and Relative Weight of Spleen}

No significant differences were noted between Met deficiency and control group at 7, 14, and 21 days of age $(P>0.05)$. At 28,35 , and 42 days of age, the weight and relative weight of spleen were decreased significantly in Met deficiency when compared with those of control groups $(P<0.05$ or $P<0.01)$. The results were showed in Table 1.

\subsection{Pathological Changes in the Spleen}

Macroscopically, spleens were smaller in Met deficiency than in control group. Histopathologically, lesions were not observed in Met deficiency during the experiment when compared with those of control group at 7 and 14 days. Lesions were appeared in Met deficiency from 21 days of age to the end of the experiment. At 21 days of age, red pulp was significantly congested (Figure 1(b)). When compared with those of control group (Figure 1(c)), the splenic corpuscle was smaller in Met deficiency than control group at 28 days of age (Figure 1(d)). At 35 and 42 days of age, lymphocytes were significantly reduced in white pulp and red pulp (Figure 1(e)). Also, the histological structure of spleen was disordered in Met deficiency (Figure 1(f)).

\subsection{Ultrastructural Changes}

No ultrastructural changes were observed in control group (Figure 2(a)). More apoptotic lymphocytes were found in the spleens in Met deficiency. The apoptotic cells showed typical condensed nuclei with crescent shapes, cytoplasmic organelles with inconspicuous structure (Figure 2(b)). The swelled or vacuolated mitochondria of lymphocytes were ultrastructurally observed in Met deficiency (Figure 2(c)).

\subsection{Cell Cycle Phase-Distribution of Splenic Cells}

To examine the dynamics of cell cycle progression, $\mathrm{G}_{0} \mathrm{G}_{1}, \mathrm{~S}$ and $\mathrm{G}_{2} \mathrm{M}$ phase distribution of the splenic cells in Met deficiency were compared with those of control group. $\mathrm{G}_{0} \mathrm{G}_{1}$ phase cell distribution gradually accumulated at 14, 28, and 42 days of age and became significantly increased $(P<0.01)$ in Met deficiency. S phase, $\mathrm{G}_{2} \mathrm{M}$ phase cell distribution and proliferation index (PI) were decreased in the splenic cells in Met deficiency at 14,28 , and 42 days of age $(P<0.05$ or $P<0.01)$. The results were showed in Table 2 .

\subsection{Annexin-V-FITC Staining Assay by Flow Cytometry}

Annexin V-FITC was used to quantitatively determine the percentage of cells that was actively undergoing apoptosis. Our data suggested that percentages of apoptotic cells in the spleen were significantly increased in Met deficiency when compared with those of control group $(P<0.01)$. The results were showed in Table 3 .

\subsection{Tunel Assay}

Tunel assay revealed that apoptotic cells had brownstain nuclei, which showed morphologic changes of condensed and irregular nuclei. Apoptotic cells were distributed in the white and red pulp of the spleens. Also, there were increased frequencies of occurrence of apoptotic

Table 1. Effect of Met deficiency on weight and relative weight of Spleen.

\begin{tabular}{|c|c|c|c|c|c|c|c|}
\hline Items & Groups & 7 days & 14 days & 21 days & 28 days & 35 days & 42 days \\
\hline \multirow{2}{*}{ Weight of Spleen (g) } & Control group & $0.086 \pm 0.029^{\mathrm{A}}$ & $0.219 \pm 0.028^{\mathrm{A}}$ & $0.506 \pm 0.046^{\mathrm{A}}$ & $0.892 \pm 0.043^{\mathrm{A}}$ & $1.336 \pm 0.106^{\mathrm{A}}$ & $1.494 \pm 0.124^{\mathrm{A}}$ \\
\hline & Met deficiency & $0.086 \pm 0.019^{\mathrm{A}}$ & $0.202 \pm 0.015^{\mathrm{A}}$ & $0.414 \pm 0.059^{A}$ & $0.689 \pm 0.062^{\mathrm{B}}$ & $0.896 \pm 0.137^{\mathrm{B}}$ & $1.020 \pm 0.140^{\mathrm{B}}$ \\
\hline \multirow{2}{*}{$\begin{array}{l}\text { Relative weight of } \\
\text { Spleen }(\mathrm{g} / \mathrm{kg})\end{array}$} & Control group & $0.693 \pm 0.242^{\mathrm{A}}$ & $0.632 \pm 0.092^{\mathrm{A}}$ & $0.751 \pm 0.067^{\mathrm{A}}$ & $0.999 \pm 0.108^{A}$ & $1.023 \pm 0.108^{\mathrm{A}}$ & $0.899 \pm 0.123^{\mathrm{A}}$ \\
\hline & Met deficiency & $0.7926 \pm 0.162^{\mathrm{A}}$ & $0.617 \pm 0.056^{\mathrm{A}}$ & $0.676 \pm 0.044^{\mathrm{A}}$ & $0.808 \pm 0.037^{\mathrm{C}}$ & $0.797 \pm 0.038^{\mathrm{B}}$ & $0.477 \pm 0.034^{\mathrm{B}}$ \\
\hline
\end{tabular}

Data are the means \pm standard deviation $(\mathrm{n}=5),{ }^{\mathrm{A}, \mathrm{B}}$ Significantly different $(P<0.01),{ }^{\mathrm{A}, \mathrm{C}}$ significantly different $(P<0.05)$. 
Table 2. Effect of Met deficiency on cell cycle phase-distribution of Spleen.

\begin{tabular}{ccccc}
\hline Groups & Item & 14 days & 28 days & 42 days \\
\hline \multirow{3}{*}{ Control group } & $\mathrm{G}_{0} \mathrm{G}_{1}$ & $78.30 \pm 1.32^{\mathrm{A}}$ & $79.17 \pm 0.61^{\mathrm{A}}$ & $79.89 \pm 0.64^{\mathrm{A}}$ \\
& $\mathrm{S}$ & $11.11 \pm 0.81^{\mathrm{A}}$ & $10.60 \pm 0.32^{\mathrm{A}}$ & $10.55 \pm 0.38^{\mathrm{A}}$ \\
& $\mathrm{G}_{2} \mathrm{M}$ & $10.58 \pm 0.56^{\mathrm{A}}$ & $10.24 \pm 0.87^{\mathrm{A}}$ & $9.56 \pm 0.45^{\mathrm{A}}$ \\
& $\mathrm{PI}^{\mathrm{a}}$ & $21.70 \pm 1.34^{\mathrm{A}}$ & $20.83 \pm 0.61^{\mathrm{A}}$ & $20.11 \pm 0.64^{\mathrm{A}}$ \\
& $\mathrm{G}_{0} \mathrm{G}_{1}$ & $81.75 \pm 0.78^{\mathrm{B}}$ & $83.60 \pm 0.93^{\mathrm{B}}$ & $87.21 \pm 0.71^{\mathrm{B}}$ \\
$\mathrm{S}$ & $8.63 \pm 0.67^{\mathrm{B}}$ & $7.83 \pm 0.43^{\mathrm{B}}$ & $5.54 \pm 0.37^{\mathrm{B}}$ & $6.35 \pm 0.41^{\mathrm{B}}$ \\
& $\mathrm{G}_{2} \mathrm{M}$ & $9.62 \pm 0.71^{\mathrm{A}}$ & $8.57 \pm 0.56^{\mathrm{C}}$ & $11.89 \pm 0.74^{\mathrm{B}}$ \\
\hline
\end{tabular}

${ }^{\mathrm{a}} \mathrm{PI}=\frac{\mathrm{S}+\mathrm{G}_{2} \mathrm{M}}{\mathrm{G}_{0} \mathrm{G}_{1}+\mathrm{S}+\mathrm{G}_{2} \mathrm{M}} \times 100 \%$. Data are the means \pm standard deviation $(\mathrm{n}=5),{ }^{\mathrm{A}, \mathrm{B}}$ Significantly different $(P<0.01),{ }^{\mathrm{A}, \mathrm{C}}$ significantly different $(P<0.05)$.

Table 3. Effect of Met deficiency on percentage of apoptotic cells in the spleen.

\begin{tabular}{|c|c|c|c|}
\hline Groups & 14 days & 28 days & 42 days \\
\hline Control group & $4.92 \pm 0.16^{\mathrm{A}}$ & $5.67 \pm 0.58^{\mathrm{A}}$ & $5.80 \pm 0.71^{\mathrm{A}}$ \\
\hline Met deficiency & $5.33 \pm 0.22^{\mathrm{A}}$ & $6.87 \pm 0.53^{\mathrm{C}}$ & $8.01 \pm 0.81^{B}$ \\
\hline
\end{tabular}

Data are the means \pm standard deviation $(\mathrm{n}=5),{ }^{\mathrm{A}, \mathrm{B}}$ Significantly different $(P<0.01),{ }^{\mathrm{A}, \mathrm{C}}$ significantly different $(P<0.05)$.

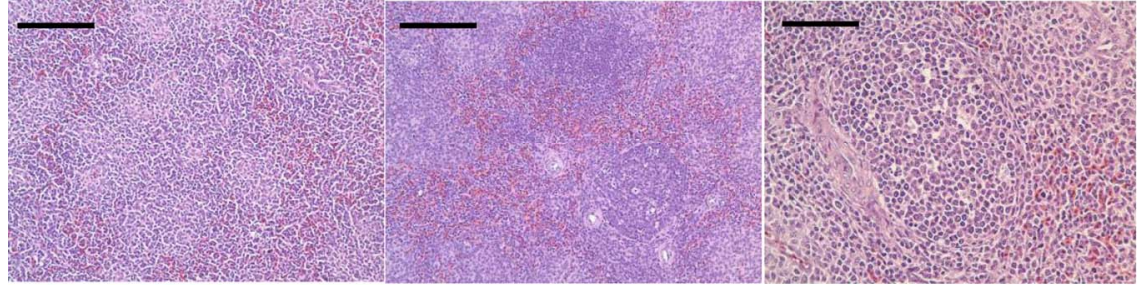

(a)

(b)

(c)

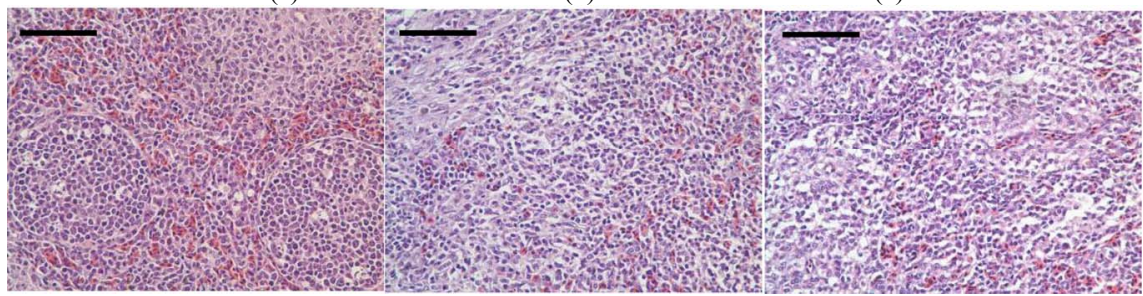

(d)

(e)

(f)

Figure 1. The histopathological changes of spleen from 21 days of age to 42 days of age. At 21 days of age, the congestion of red pulp is appeared in Met deficiency $((b)$, bar $=200 \mu \mathrm{m})$ when compared with those of control group ( $(\mathrm{a}), \mathrm{bar}=200 \mu \mathrm{m})$; (c) The spleen of control group of 28 days; (d) At 28 days of age, congestion of red pulp is also observed, and the splenic corpuscle is smaller in Met deficiency than in control group; (e) At 35 days of age, the lymphocytes are significantly decreased in number in white pulp and red pulp in Met deficiency; (f) At 42 days of age, the lymphocytes in splenic corpuscle are significantly decreased and the histological structure of spleen is disordered in Met deficiency $((\mathrm{c}),(\mathrm{d}),(\mathrm{e}),(\mathrm{f}), \mathrm{HE}$. Bars $=50 \mu \mathrm{m})$.

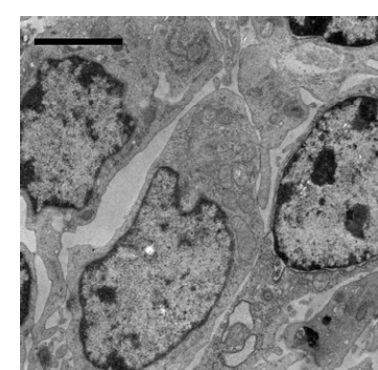

(a)

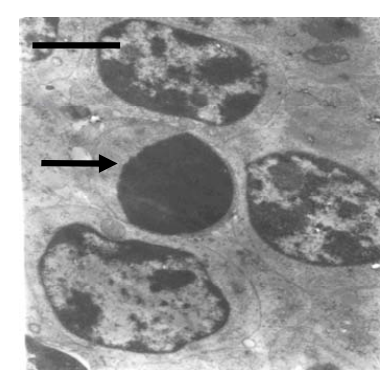

(b)

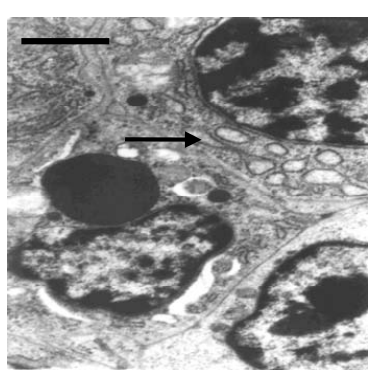

(c)

Figure 2. (a) Spleen of chicken in control group. Bar $=2 \mu \mathrm{m}$; (b) Spleen chicken in Met deficiency. The apoptosis cell is presented in figure. Apoptotic cells have condensed nuclei with petal-like $(\rightarrow)$ in Met deficiency (Bar $=2 \mu \mathrm{m})$; (c) The mitochondria of lymphocytes are swelled or vacuolated with degenerating cristae in Met deficiency $(\rightarrow)(\mathrm{Bar}=2 \mu \mathrm{m})$. 
cells in Met deficiency when compared with those of control group (Figure 3).

\subsection{Changes of the Oxidative Markers in Serum and Spleen}

As showed in Tables $\mathbf{4}$ and $\mathbf{5}$, the serum and splenic SOD and GSH-Px activities were significantly lower $(P$ $<0.01$ or $P<0.01)$ in Met deficiency than in control group from 28 to 42 days of age. The splenic and serum MDA contents were markedly increased in Met deficiency at 28 and 42 days of age compared with those of control group during the experiment, as described in Table 6. At the same time, the abilities to inhibit hydroxyl radicals were greatly decreased (Table 7).

\section{DISCUSSION}

It is well known that spleen is the biggest peripheral immune organ and plays an important role in immune reaction. In the present study, the weight and relative weight of spleen were used to judge the development of spleens. The results showed that the weight and relative weight of spleens were decreased in Met deficiency, which indicated that the development of the spleens was impacted by Met deficiency.

Splenic nodules are where B lymphocytes gather and mature, and that the periarterial lymphatic sheath consists of matured $\mathrm{T}$ lymphocytes. In the present study, histopathological results in Met deficiency showed that lymphopenia was appeared in white pulp (including splenic corpuscle) and red pulp, which indicated suppression of $\mathrm{B}$ cell and $\mathrm{T}$ cell proliferation that would reduce growth index and decreased number of lymphocytes of spleen. The swelled or vaculated mitochondria of lymphocytes were ultrastructurally observed in Met deficiency. The lymphopenia could be a reason for the decreasing weight of spleen. The mitochondrial injury of the lymphocytes reflected the injury of splenocytes. It was suggested that the splenocytes and splenic tissue was finally impaired by Met deficiency.

The eukaryotic cell cycle is divided into four major phases as follows: the $\mathrm{G}_{1}$ phase before DNA replication, the periods of DNA synthesis ( $\mathrm{S}$ phase), the $\mathrm{G}_{2}$ phase before cell division (M phase) [19]. In the present study, Met deficiency caused an increase in $\mathrm{G}_{1}$ phase cells that corresponded to a decrease in S phase cells and PI in spleens. The results also showed that the progression of lymphocytes from the $G_{0} / G_{1}$ to $S$ phases was seriously impaired by Met deficiency. The mechanism of effect of Met on lymphocyte proliferation has not been clear. A possibility was that Met could affect lymphocyte proliferation by changing the production of proteins responsible for proliferation, such as cyclins and IL-2 because Met could suppress protein synthesis [4,20].

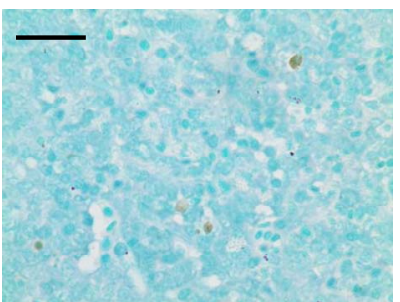

(a)

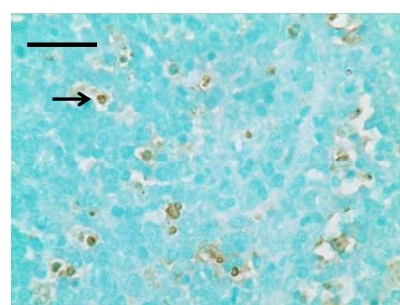

(b)
Figure 3. There are several apoptotic cells in control group (a). The numbers of apoptotic cells (which showed morphologic changes of condensed and irregular nuclei) $(\rightarrow)$ are increased in deficiency group (b) when compared with those of control group. Bars $=20 \mu \mathrm{m}$.

In the present study, AnnexinV-FITC staining assay showed that the percentage of apoptotic cells in the spleens was significantly increased in Met deficiency. Ultrastructurally, more apoptotic cells could also been observed in spleen. Tunel assay revealed that apoptotic cells with brown-stained nuclei were distributed within the white and red pulp of the spleens with increased frequency of occurrence in methionine deficiency group in comparison with those of control group. The mechanisms of apoptosis are associated with accumulation of the ceramide and activation of caspase. It is reported that Met deficiency could activate one or more pathways for initiating apoptosis that ultimately converge on a common execution pathway [13]. According to the results in the present study, Met deficiency-induced apoptosis was associated with following factors: 1) The mitochondria damage. In the present study, swelled or vacuolated mitochondria of lymphocytes were ultrastructurally observed in methionine deficiency. Due to mitochondrial injury, mitochondrial apoptogenic proteins(such as caspase) were released to the cytoplasm, and the apoptotic process was finally induced $[21,22] .2$ ) The accumulation of free radicals. In the present study, the abilities to inhibit hydroxyl radicals were reduced in serum and spleen (Table 7). Increased and accumulated free radicals in the body and spleen could induce splenocyte apoptosis. 3) The cell apoptosis was related to the accumulation of cells in $\mathrm{G}_{0} / \mathrm{G}_{1}$ phage. The above discussion could help us understanding the reason of increased splenocyte apoptosis induced by Met deficient chickens.

It is widely known that SOD and GSH-Px are antioxidant enzymes, which are considered as an important physiological antioxidant defense mechanism in removing excess oxygen negative ion [23]. Methionine acts a precursor amino acid for low molecular mass antioxidant glutathione which protects the cells from oxidative damage and plays vital role in detoxification [24-26]. MDA is the end products of lipid peroxidation. In the present study, the SOD and GSH-Px activities, the ability of inhibition of Hydroxyl Radical as well as the MDA con- 
Table 4. Change of the splenic and serum SOD activities.

\begin{tabular}{ccccc}
\hline Item & Groups & 14 days & 28 days & 42 days \\
\hline \multirow{2}{*}{ Serum SOD (U/ml) } & Control group & $125.45 \pm 5.74^{\mathrm{A}}$ & $160.04 \pm 4.19^{\mathrm{A}}$ & $185.41 \pm 4.33^{\mathrm{A}}$ \\
& Met deficiency & $127.20 \pm 4.55^{\mathrm{A}}$ & $152.65 \pm 6.56^{\mathrm{C}}$ & $163.16 \pm 5.28^{\mathrm{B}}$ \\
Spleen SOD & Control group & $260.65 \pm 13.95^{\mathrm{A}}$ & $275.46 \pm 12.50^{\mathrm{A}}$ & $243.31 \pm 9.91^{\mathrm{A}}$ \\
(U/mgprot) & Met deficiency & $260.75 \pm 8.43^{\mathrm{A}}$ & $259.39 \pm 9.36^{\mathrm{C}}$ & $217.06 \pm 9.89^{\mathrm{B}}$ \\
\hline
\end{tabular}

Data are the means \pm standard deviation $(\mathrm{n}=5),{ }^{\mathrm{A}, \mathrm{B}}$ Significantly different $(P<0.01),{ }^{\mathrm{A}, \mathrm{C}}$ significantly different $(P<0.05)$.

Table 5. Change of the splenic and serum GSH-Px activities.

\begin{tabular}{ccccc}
\hline Item & Groups & 14 days & 28 days & 42 days \\
\hline \multirow{2}{*}{ Serum GSH-PX(U) } & Control group & $438.92 \pm 27.89^{\mathrm{A}}$ & $466.28 \pm 17.96^{\mathrm{A}}$ & $411.57 \pm 36.01^{\mathrm{A}}$ \\
& Met deficiency & $514.69 \pm 23.29^{\mathrm{A}}$ & $427.58 \pm 26.85^{\mathrm{B}}$ & $325.18 \pm 32.69^{\mathrm{B}}$ \\
Spleen & Control group & $710.54 \pm 43.16^{\mathrm{A}}$ & $695.32 \pm 50.48^{\mathrm{A}}$ & $674.56 \pm 29.70^{\mathrm{A}}$ \\
GSH-PX(U) & Met deficiency & $670.59 \pm 33.11^{\mathrm{A}}$ & $617.50 \pm 42.65^{\mathrm{C}}$ & $525.92 \pm 37.21^{\mathrm{B}}$ \\
\hline
\end{tabular}

Data are the means \pm standard deviation $(\mathrm{n}=5),{ }^{\mathrm{A}, \mathrm{B}}$ Significantly different $(P<0.01),{ }^{\mathrm{A}, \mathrm{C}}$ significantly different $(P<0.05)$.

Table 6. Change of the splenic and serum MDA contents.

\begin{tabular}{ccccc}
\hline Item & Groups & 14 days & 28 days & 42 days \\
\hline \multirow{2}{*}{ Serum MDA (nmol/ml) } & Control group & $1.58 \pm 0.08^{\mathrm{A}}$ & $3.33 \pm 0.13^{\mathrm{A}}$ & $3.00 \pm 0.18^{\mathrm{A}}$ \\
& Met deficiency & $2.37 \pm 0.14^{\mathrm{A}}$ & $4.63 \pm 0.33^{\mathrm{C}}$ & $5.06 \pm 0.40^{\mathrm{B}}$ \\
\multirow{2}{*}{ Spleen MDA (nmol/mgprot) } & Control group & $3.02 \pm 0.27^{\mathrm{A}}$ & $3.60 \pm 0.22^{\mathrm{A}}$ & $4.18 \pm 0.27^{\mathrm{A}}$ \\
& Met deficiency & $3.27 \pm 0.29^{\mathrm{A}}$ & $5.08 \pm 0.44^{\mathrm{C}}$ & $6.97 \pm 0.39^{\mathrm{B}}$ \\
\hline
\end{tabular}

Data are the means \pm standard deviation $(\mathrm{n}=5),{ }^{\mathrm{A}, \mathrm{B}}$ Significantly different $(P<0.01),{ }^{\mathrm{A}, \mathrm{C}}$ significantly different $(P<0.05)$.

Table 7. The abilities to inhibit hydroxyl radicals.

\begin{tabular}{ccccc}
\hline Item & Groups & 14 days & 28 days & 42 days \\
\hline $\begin{array}{c}\text { Serum Hydroxyl Radical } \\
\text { (U/ml) }\end{array}$ & Control group & $492.40 \pm 19.83^{\mathrm{A}}$ & $492.41 \pm 13.22^{\mathrm{A}}$ & $466.32 \pm 18.6^{\mathrm{A}}$ \\
& Met deficiency & $490.45 \pm 17.87^{\mathrm{A}}$ & $467.32 \pm 21.05^{\mathrm{C}}$ & $414.65 \pm 16.5^{\mathrm{C}}$ \\
Spleen Hydroxyl Radical & Control group & $131.74 \pm 11.47^{\mathrm{A}}$ & $150.04 \pm 10.00^{\mathrm{A}}$ & $186.86 \pm 11.52^{\mathrm{A}}$ \\
$(\mathrm{U} /$ mgprot) & Met deficiency & $126.51 \pm 11.14^{\mathrm{A}}$ & $119.35 \pm 9.78^{\mathrm{B}}$ & $158.79 \pm 11.92^{\mathrm{B}}$ \\
\hline
\end{tabular}

Data are the means \pm standard deviation $(\mathrm{n}=5),{ }^{\mathrm{A}, \mathrm{B}}$ Significantly different $(P<0.01),{ }^{\mathrm{A}, \mathrm{C}}$ significantly different $(P<0.05)$.

tents in spleen and serum were measured to assess the oxidative status of spleen. The results showed that the lipid peroxidation level were much higher in Met deficiency than in control group (Table 6). At the same time, SOD and GSH-Px activities, and the abilities to inhibit hydroxyl radicals were reduced (Tables 3, 5 and 7). The results suggested that Met deficiency might induce oxidative damage and cause further lipid peroxidation, which could involve the accumulation of free radicals and finally impair the biomembrane structure of splenocytes. And oxidative damage may probably be a reasonable pathway for the increased apoptotic splenocytes and the injury of the splenocytes. In conclusion, Met deficiency was found to cause the decreased activities of antioxidant enzymes, increased of lipid peroxidation and finally induce apoptosis in the spleen of chickens. Oxi- dative stress induced by Met deficiency thus plays an important role in the pathogenesis of Met deficiency.

\section{CONCLUSION}

According to the results in the present study and the aforementioned discussion, it is concluded that Met deficiency can restrain the development of spleen by cell cycle arrest and increased apoptosis, cause splenic lesions and reduce splenic antioxidant function. The splenic function should be finally impaired in chickens and then the immune function could be impacted in chickens.

\section{ACKNOWLEDGEMENT}

The study was supported by the program for Changjiang scholars and innovative research team in university (IRT 0848) and the Educa- 
tion Department (09ZZ017) and Scientific department of Sichuan Province.

\section{REFERENCES}

[1] Carew, L.B., McMurtry J.P. and Alster, F.A. (2003) Effects of methionine deficiencies on plasma levels of thyroid hormones, insulin-like Growth Factors-I and -II, Liver and Body Weights and Feed Intake in Growing Chickens. Poultry Science, 82, 1932-1938.

[2] Cummins, A.G., Bolin, T.D., Duncombe, V.M. and Davis, A.E. (1986) The effect of methionine and protein deficiency in delaying expulsion of Nippostrongylus brasiliensis in the rat. The American Journal Clinical Nutrition, 44, 857-862.

[3] Dunlevy, L.P.E., Burren, K.A., Chitty, L.S., Copp, A.J. and Greene, N.D.E. (2006) Excess methionine suppresses the methylation cycle and inhibits neural tube closure in mouse embryos. FEBS Letters, 11, 2803-2807. doi:10.1016/j.febslet.2006.04.020

[4] Kano, Y., Sakamoto, S., Kasahara, T., Kusumoto, K., Hida, K., Suda, K., Ozawa, K., Miura, Y. and Takaku, F. (1982) Methionine dependency of cell growth in normal and malignant hematopoietic cells. Cancer Research, 42, 3090-3092.

[5] Cummins, A.G., Duncombe, V.M., Bolin, T.D. and Davis, A.E. (1985) Reversible nutritional myopathy with myotonia in the protein-deficient rat given methionine. Australian Journal Experimental Biology and Medical Science, 63, 127-137.

[6] Mori, N. and Hirayama, K. (2000) Long-term consumption of a methionine-supplemented diet increases iron and lipid peroxide levels in rat liver. The Journal of Nutrition, 130, 2349-2355.

[7] Feo, F., Pascale, R., Garcea, R., Daino, L., Pirisi, L., Frassetto, S., Ruggiu, M.E., Di Padova, C. and Stramentinoli, G. (1986) Effect of the variations of S-adeno-sylL-methionine liver content on fat accumulation and ethanol metabolism in ethanol-intoxicated rats. Toxicology and Applied Pharmacology, 2, 331-341. doi:10.1016/0041-008X(86)90310-8

[8] Swain, B.K. and Johri, T.S. (2000) Effect of supplemental methionine, choline and their combinations on the performance and immune response of broilers. British Poultry Science, 41, 83-88. doi:10.1080/00071660086457

[9] Tsiagbe, V.K., Cook, M.E., Harper, A.E. and Sunde, M.L. (1987) Enhanced immune responses in broiler chicks fed methionine-supplemented diets. Poultry Science, 66, 11471154.

[10] Tsiagbe, V.K., Cook, M.E., Harper, A.E. and Sunde, M.L. (1987) Efficacy of cysteine in replacing methionine in the immune responses of broiler chicks. Poultry Science, 66, 1138-1146.

[11] Klasing, K.C. and Barnes, D.M. (1988) Decreased amino acid requirements of growing chicks due to immunologic stress. The Journal of Nutrition, 118, 1158-1164.
[12] Konashi, S., Takahashi, K. and Akiba, Y. (2000) Effects of dietary essential amino acid deficiencies on immunological variables in broiler chickens. British Journal of Nutrition, 83, 449-456.

[13] Yen, C.L.E, Mar, M.H., Craciunescu, C.N., Edwards, L.J. and Zeisel, S.H. (2002) Deficiency in Methionine, Tryptophan, Isoleucine, or Choline Induces Apoptosis in Cultured Cells. The Journal of Nutrition, 132, 1840-1847.

[14] Benevenga, N.J. (1974) Toxicities of methionine and other amino acids. Journal of Agricultural and Food Chemistry, 22, 2-9. doi:10.1021/jf60191a036

[15] Benevenga, N.J. and Steele, R.D. (1984) Adverse effects of excessive consumption of amino acids. Annual Review of Nutrition, 4, 157-181. doi:10.1146/annurev.nu.04.070184.001105

[16] Cui, H.M., Fang, J. and Peng, X. (2003) Pathology of the thymus, spleen and bursa of Fabricius in zinc-deficient ducklings. Avian Pathology, 32, 259-263. doi:10.1080/10307945031000097840

[17] Peng, X., Cui, Y., Cui, W., Deng, J.L. and Cui, H.M. (2009) The decrease of relative weight, lesions, and apoptosis of Bursa of Fabricius induced by excess dietary selenium in chickens. Biological Trace Element Research, 131, 33-42. doi:10.1007/s12011-009-8345-6

[18] Bradford, M.M. (1976) A rapid and sensitive method for the quantitation of microgram quantities of protein utilizing the principle of protein-dye binding. Analytical Biochemistry, 72, 248-254. doi:10.1016/0003-2697(76)90527-3

[19] Pines, J. (1995) Cyclins, CDKs and cancer. Seminars Cancer Biology, 6, 63-72. doi:10.1006/scbi.1995.0009

[20] Bonham, M., O’Connor, J.M., Hannigan, B.M. and Strain JJ. (2002) The immune system as a physiological indicator of marginal copper status. British Journal of Nutrition, 87, 383-403. doi:10.1079/BJN2002558

[21] Palmer, A.M., Greengrass, P.M. snd Cavalla, D. (2000) The role of mitochondria in apoptosis. Drug News Perspect, 13, 378-384.

[22] Raisbeck, M.F., Siemion, R.S. and Smith, M.A. (2006) Modest copper supplementation blocks molybdenosis in cattle. Journal of Veterinary Diagnostic Invest, 18, 566572. doi:10.1177/104063870601800607

[23] Halliwell, B. and Chirico, S. (1993) Lipid peroxidation: its mechanism, measurement, and significance. The American Journal Clinical Nutrition, 57, 715S-725S.

[24] Reed, D.J. and Orrenius, S. (1977) The role of methionine in glutathione biosynthesis by isolated hepatocytes. Biochemical and Biophysical Research Communications, 77, 1257-1264. doi:10.1016/S0006-291X(77)80115-0

[25] Reed, D.J. (1990) Glutathione: toxicological implications. Annual Review Pharmacology and Toxicology, 30, 603631. doi:10.1146/annurev.pa.30.040190.003131

[26] Meister, A. (1981) On the cycles of glutathione metabolism and transport. Current Topics Cell Regulation, 18, 21-58. 